\title{
Variations and Misconceptions of Asthma Terminology, Triggers and Therapy among the Caregivers of Asthmatic Children in Makkah, Saudi Arabia
}

\author{
Mohammed Abu Aish ${ }^{1 *}$, Miral Talal Fadhl'2, Khadijah Ahmad Alzhrani ${ }^{2}$ and \\ Abdullah Aburiziza ${ }^{3}$ \\ 'Assistant Professor, Department of Pediatrics, Umm Al-Qura University (UQU), Makkah, Saudi Arabia; \\ maabuaish@uqu.edu.sa \\ ${ }^{2}$ College of Medicine, Umm Al-Qura University (UQU), Makkah, Saudi Arabia; miral.fadhl@gmail.com, \\ khadijahahmad1995@gmail.com \\ ${ }^{3}$ Assistant Professor, Department of Pediatrics, Umm Al-Qura University (UQU), Makkah, Saudi Arabia; \\ ajaburiziza@uqu.edu.sa
}

\begin{abstract}
Asthma is the most common chronic disease of childhood leading to an ongoing burden on the emergency departments all around the world. The present study was conducted with the aim to assess the awareness and misconceptions related to the terminology, triggers and management among the caregivers of asthmatic children in Makkah, Saudi Arabia. An observational cross-sectional study was conducted among the asthmatic children above 6 months of age at the Maternity and Children's Hospital in Makkah, Saudi Arabia during the period between March 2018 and July 2018. Data were collected by a structured questionnaire that includes demographic data, knowledge and awareness of the terminology, severity, triggers, follow-up and management of the disease with a focus on Metered-Dose Inhalers (MDIs), nebulizer therapy and Inhaled Cortico-Steroids (ICS). A total 242 children were included in the study $64.5 \%$ were males, $35.5 \%$ were females. A majority (71.5\%) of caregivers believed that nebulizers are more effective than MDIs to treat their children. Among the 242 children, $47.1 \%$ use spacer devices regularly and only $40.5 \%$ of them have used ICS. The main reason for not using steroid inhalers and spacer devices as stated by most caregivers ( $68 \%$ and $49.3 \%$ respectively). was "never recommended by physicians". $73.1 \%$ of the children had no Asthma follow up outside the ED. 73.7\% of caregivers who reported having a smoker in their homes did not know the harmful effects of smoking on their children. Many misconceptions about the terminologies, triggers, the nature of the ED medications and outpatient treatment were found among the caregivers of the children included in the study. Physicians poor adherence to current asthma treatment guidelines and the lack of well structured follow up and educational programs may be contributing to the caregivers inconsistencies with outpatient treatment and follow up.
\end{abstract}

Keywords: Asthma Therapy, Bronchial Asthma, Inhalers, Misconception, Triggers

\section{Introduction}

Asthma is the most common chronic disease of childhood $^{1}$. It is considered as the third leading cause of hospitalization among children under 15 years of age $^{2}$ with a prevalence rate of about 300 million people across the world ${ }^{3}$. In Saudi Arabia, the prevalence rate in the general population varies between $15-25 \%{ }^{4}$. Asthma

${ }^{*}$ Author for correspondence 
manifests as recurrent attacks of shortness of breath associated with wheezing, cough and chest tightness. Factors that contribute to asthma exacerbations include upper respiratory tract infections, allergens such as dust mites, smoking, exercise, and others.

The management of asthma includes pharmacological and non-pharmacological interventions aimed to maintain symptom-free lifestyle and to reduce future relapses. Despite the improvement of asthma therapy, acute exacerbations of asthma continue to be a major issue leading to overburden of the health care system ${ }^{5}$. A study by Al-Jahdali, et al. in major hospitals of Saudi Arabia found that only $5 \%$ of the patients were completely controlled, $31 \%$ were partially controlled, and $64 \%$ were uncontrolled from their asthma symptoms $s^{6}$. It is well known that asthma education programs can improve the quality of life of asthmatic patients. In case of children, educational programs should target the caregivers of the children. These programs are important part of the management strategy and their effectiveness in improving asthma have been cited by various studies ${ }^{7,8}$.

Most of the previous studies conducted in Saudi Arabia only assessed the caregivers' awareness regarding childhood asthma, but studies concerned with the assessment of the knowledge about its management are very limited. Hence, our study was conducted with the aim to assess the awareness and misconceptions regarding asthma and its management among the caregivers of asthmatic children in Makkah, Saudi Arabia.

\section{Materials and Methods}

An observational cross-sectional study was conducted in the Emergency Department (ED) of the Maternity and Children's Hospital in Makkah, Saudi Arabia during the period between March 2018 and July 2018. The study included asthmatic children above the age of 6 months presenting to the ED with acute asthma exacerbations. Patients were defined as "asthmatics" if they presented with more than 3 attacks of wheezing that responded to bronchodilator therapy or patients previously diagnosed with bronchial asthma by a specialist. Children less than 6 months and caregivers not willing to participate were excluded from the study. A total of 242 patients and their caregivers were selected for the study using convenience sampling. The study was approved by the Institutional Review Board of Umm Al-Qura University.
Data were collected by a structured questionnaire which was designed by the principal investigator and validated by the statistical department of Umm Al-Qura University. The questionnaire was divided into three sections. The first section consists of demographic data including age, gender, history of other allergies, family history of asthma and family history of other allergies. The second section assesses the knowledge and awareness related to the terminology (02 questions), severity (06 questions), triggering factors (03 questions) and the follow-up (01 question) of the disease. The third section includes questions related to the management of the disease with a focus on MDIs, nebulizer therapy and ICS (08 questions).

Multiple training sessions with the research team were held before starting the study and the questionnaire was uploaded on iPad Pro devices. Paper version of the questionnaire was available in case of technical difficulties with iPads. After the initial assessment and confirmation of the diagnosis of bronchial asthma by a physician, parental consent was taken.

Data were recorded by the research team students daily during their shifts (4pm to 12am) under the supervision of the study principal investigator. All the asthma patients visiting the hospital were first triaged on the basis of their Pediatric Respiratory Assessment Measure (PRAM) score. The patients with PRAM score 0-3 (mild cases) come to the green zone in the ED, PRAM score 4-7 (moderate cases) to the yellow zone and PRAM score 8-12 (severe cases) to the red zone. The caregivers of the patients fulfilling the inclusion criteria were interviewed about their children's condition. The interviews took place while the children were receiving bronchodilator therapy in the treatment rooms. Each patient in the study was given a serial study code and initials to ensure no repetition for any patient coming back as a revisit to the emergency room.

\subsection{Statistical Analysis}

During the study period, no technical difficulties were encountered so all data were entered electronically via the iPads and were transferred into an excel sheet in the research server. IBM SPSS software, version 23 was used for descriptive data analysis; the results were then tabulated for calculation of response percentage. 


\section{Results}

The study included 242 individuals who fitted the inclusion criteria. Among the population studied, males were $156(64.5 \%)$ and females were $86(35.5 \%)$. Eightyseven $(36 \%)$ of patients were 6 months to 2 years old, 96(39.7\%) were 2 to 6 years old, 55(22.7\%) were 6 to 12 years old and $4(1.7 \%)$ were 12 to 18 years old.

\subsection{Caregivers' Awareness and Knowledge of Asthma Diagnosis, Terminologies, Triggers and Follow up}

Only $128(52.9 \%)$ of caregivers answered with yes when asked if their children have asthma, while 94(38.8\%) answered with no and 20(8.3\%) did not know or were not sure whether their children have asthma or not. There was a clear overlap in the terms used to describe the condition among caregivers of asthmatic children. Approximately, $60.9 \%$ have a clear overlap between the terminologies related to both asthma and chest allergy.

When asked about the triggering factors of their children's asthma, 101(41.70\%) of the caregivers believed that the weather change is the main triggering factor followed by common cold and viral illness in 98 (40.50\%). Other triggers reported were: dust furniture/carpet 96 (39.70\%), incense and strong odours 90 (37.20\%), perfumes 89 ( $36.80 \%)$, smoking 27 (11.20\%), exercise $20(8.30 \%)$, foods $14(5.80 \%)$ and others 25 (10.30\%). $9(3.70 \%)$ of the caregivers did not know or were not sure about the triggering factors of asthma (Figure 1).

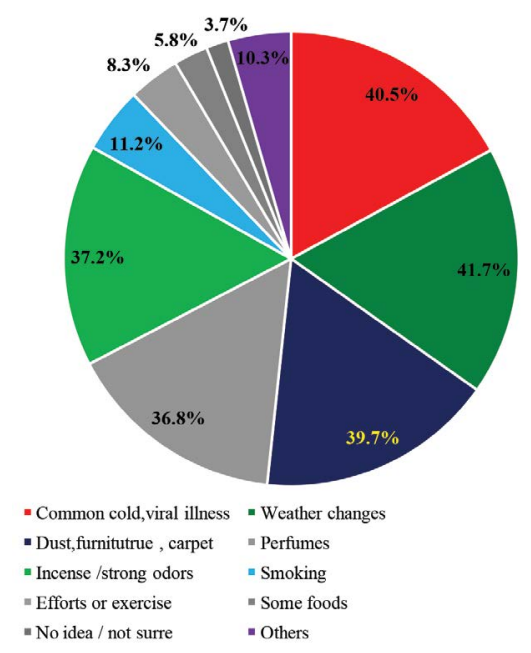

Figure 1. Caregivers' reported Asthma triggers in their Children
76 Caregivers answered with (yes) when asked if someone smokes in their homes, Among those caregivers, only $20(26.3 \%)$ believed/knew that smoking is a trigger for asthma in their children, while 56(73.7\%) of them did not recognize that smoking is a trigger for asthma. Among 242 asthmatic children, $177(73.1 \%)$ of them only came to the ED for treatment of their asthma exacerbations and they were not following with any specialist/physician outside the ED, 45(18.6\%) are followed by a physician (pediatrician or pulmonologist), $8(3.3 \%)$ of them saw a physician in the past but not currently following and $12(4.9 \%)$ of caregivers were either not sure or could not provide the answer to this question.

\subsection{Caregivers' Awareness and Knowledge of Different Asthma Treatment Modalities}

128(52.9\%) of the caregivers did not know that the nebulized salbutamol they receive in ED is the same as the salbutamol MDIs, $87(36 \%)$ of them knew both were the same medication, $14(5.8 \%)$ were not sure and 13(5.4\%) did not answer the question. $173(71.5 \%)$ of caregivers thought that nebulized medications are more effective than MDIs, 19(7.9\%) thought MDIs are more effective, $31(12.8 \%)$ answered that both MDIs and nebulizers are equally effective, $8(3.3 \%)$ did not know or were not sure and $11(4.5 \%)$ did not answer the question.

When the caregivers were asked about the usage of salbutamol/bronchodilators MDIs at some point in the management of their children, 164(67.8\%) answered with yes and $78(32.2 \%)$ of them stated that they have not used Salbutamol/bronchodilator MDIs before. When they were asked about the usage of inhaled cortico-steroid MDIs, 98(40.5\%) answered with yes and 144(59.5\%) of them stated that they have not used ICS before. The reasons for not using Salbutamol and steroid MDIs were summarized in (Table 1). The caregivers were asked about the current treatment modality, 110(45.3\%) of them were using Salbutamol MDIs, 42(17.4\%) were using steroid MDIs and $37(15.3 \%)$ were not currently using any medication for asthma treatment as an outpatient.

When caregivers were asked about the use of spacer devices (Table 2), most of them 114(47.1\%) indicated they have used them. The main cause of not using the spacers as stated by 34 (49.3) caregivers was the lack of recommendation by doctors. 
Table 1. Caregivers' reasons for not using bronchodilators and ICS MDIs

\begin{tabular}{|c|c|c|}
\hline Reasons & Response & N (\%) \\
\hline \multirow{7}{*}{$\begin{array}{l}\text { Reasons for } \\
\text { not using } \\
\text { Salbutamol } \\
\text { MDIs }\end{array}$} & Was not prescribed for the child & $41(52.5)$ \\
\hline & Did not use due to busy work & $1(1.3)$ \\
\hline & $\begin{array}{l}\text { Did not think MDIs are effective } \\
\text { as nebulizers }\end{array}$ & $4(5.1)$ \\
\hline & $\begin{array}{l}\text { The child was getting better and } \\
\text { did not need it }\end{array}$ & $3(3.8)$ \\
\hline & Fear of abuse & $8(10.2)$ \\
\hline & Fear of side effects & $1(1.3)$ \\
\hline & Do not know how to use & $1(1.3)$ \\
\hline \multirow{9}{*}{$\begin{array}{l}\text { Reasons for } \\
\text { not using } \\
\text { ICS MDIs }\end{array}$} & Was not prescribed for the child & $98(68)$ \\
\hline & Did not use due to busy work & $1(0.7)$ \\
\hline & $\begin{array}{l}\text { Did not think MDIs are effective } \\
\text { as nebulizers }\end{array}$ & $2(1.4)$ \\
\hline & $\begin{array}{l}\text { The child was getting better and } \\
\text { did not need it }\end{array}$ & $4(2.8)$ \\
\hline & Fear of abuse & $7(4.7)$ \\
\hline & Fear of side effects & $1(0.7)$ \\
\hline & Not available / not found & $2(1.4)$ \\
\hline & Do not know how to use & $1(0.7)$ \\
\hline & Stopped by doctor / stopped & $1(0.7)$ \\
\hline
\end{tabular}

Table 2. Use of spacer devices and the reasons for not using them

\begin{tabular}{|c|c|c|}
\hline Device use & Response & $\mathbf{N}(\%)$ \\
\hline \multirow{3}{*}{$\begin{array}{l}\text { Spacer } \\
\text { device use }\end{array}$} & No & $69(28.5)$ \\
\hline & Yes & $114(47.1)$ \\
\hline & Sometimes & $13(5.4)$ \\
\hline \multirow{5}{*}{$\begin{array}{l}\text { Reason for } \\
\text { not using } \\
\text { spacer } \\
\text { devices }\end{array}$} & I do not know its importance & $22(31.8)$ \\
\hline & Not recommended by doctor & $34(49.3)$ \\
\hline & $\begin{array}{l}\text { My child doesn't need it because } \\
\text { she/he became older }\end{array}$ & $8(11.6)$ \\
\hline & I could not afford it & $9(13)$ \\
\hline & Others & $6(8.7)$ \\
\hline
\end{tabular}

\section{Discussion}

The present study was aimed to assess the parental awareness and misconceptions towards the diagnosis, terminology, triggers and management options specifically related to the use of inhaled steroids, MDIs and spacer devices among children with Asthma.

Only $52.9 \%$ of the caregivers knew the correct diagnosis of their children and the majority of them $(60.9 \%)$ have confusion regarding the terminologies between the terms asthma and chest allergy. Gajanan, et al. study found that only $20 \%$ of the parents were aware about the diagnosis of bronchial asthma in their children'. A previous study done in Saudi Arabia showed that $60.2 \%$ of mothers had poor knowledge scores about the symptoms, mechanism, aggravating factors and complications of bronchial asthma ${ }^{10}$. Another study conducted in Lebanon found that the majority of parents did not recognize asthma by its name but referred to it as chest allergy or recurrent dyspnea ${ }^{11}$. To eliminate this confusion, physicians should emphasize and use the term asthma instead of using the term "chest allergy" because when families understand the chronic nature of asthma, they will take the condition more seriously and they will be more consistent with treatment and follow-up.

In our study, only $73.7 \%$ of caregivers who reported having a smoker in their homes did not know the harmful effects of smoking on their children whereas, it was proved in previous literature that exposure to smoking either secondary, tertiary or environmental can decrease the ICS efficacy ${ }^{12}$ and significantly increased the risk of asthma exacerbation. Furthermore, maternal smoking has a high impact in increasing the likelihood of the child to have asthma ${ }^{13,14}$. A study conducted by Gonzalez et al., showed that $51 \%$ of the study population who were exposed to Environmental Tobacco Smoke (ETS) showed a high prevalence of asthma symptoms ${ }^{15}$. Other studies proved that smoking is a trigger of asthma and contributes to asthma exacerbations, recurrent $\mathrm{ED}$ visits and hospitalizations ${ }^{16,17}$.

Our study found that $41.7 \%$ of caregivers believed that weather change is one of the main triggering factor for their children's asthma, which is higher than other studies like Gajanan, et al. study where $31.3 \%$ of parents believed that asthma is triggered by weather changes ${ }^{9}$. $37.2 \%$ of caregivers considerd the incense and strong odors as triggers for the exacerbations of asthma in their children. In our culture, incense is traditionally used in 
ceremonies but many housekeepers use it regularly at home for different rituals. Incense is one of the triggering factors of asthma exacerbations . A study done in Oman showed that $33.1 \%$ and $40.7 \%$ of asthmatic children in Muscat and Sharqiyah, respectively had worsening wheezing symptoms due to the frequent use of bakhour (traditional incense) at home, which made bakhour the fourth most common trigger of asthma symptoms after dust, weather and viral upper respiratory tract infection in both regions ${ }^{18}$. The results of our study suggest that educational programs directed towards the caregivers of asthmatic children should explain the effects of smoking and other triggers on disease control and the patients' quality of life. It is very important to explain in our educational programs that asthmatic children who are properly treated and followed up will have less airway hyper reactivity and will be less venerable to some of those triggers with time.

The management of asthma includes pharmacological and non-pharmacological options. Pharmacological modalities consist of reliever medications and controller medications. Reliever medications are used to relieve breakthrough symptoms in worsening and exacerbated asthma while, controller medications are used as maintenance therapy. Among all of the medications used, the ICS are considered the mainstay of asthma treatment ${ }^{19}$. A study conducted in Saudi Arabia showed that $60.3 \%$ of caregivers were concerned about the side effects of ICS and $32 \%$ were afraid that their children may depend completely on asthma medications ${ }^{23}$. Another study showed that $48 \%$ of caregivers believed MDIs were addictive,56\% worried about MDIs' side effects, and 76\% worried about using $\mathrm{ICS}^{24}$. Our study showed that the majority of parents were not prescribed ICS by physicians and not because of worry about the side effects as shown in other studies. This emphasize that physicians role in the ED in treating asthma should include prescribing and educating parents about the importance of ICS in the long term treatment and control of Asthma.

When it comes to the mode of delivery of asthma medications, many studies have shown that MDIs are effective as nebulizer therapy ${ }^{20,21}$. Our study shows that a significant number of caregivers (52.9\%) are unaware of the fact that the nebulized bronchodilators used in the ED are the same medications as the prescribed bronchodilators MDIs. Many thought that nebulizers are superior to MDIs in treating their children's symptoms, whereas, it was proved in the previous literature that the use of MDI-spacer and nebulizers in ED have the same response among asthmatic children ${ }^{22}$. This is a major concern that affects compliance with MDIs at home if families do not know or believe in the effect of MDIs.

MDIs with a spacer device need minimal preparation and less time to administer and less risk of side-effects, also are cheaper and more portable compared to nebulizers ${ }^{22}$. Cheng et al., found that among children who arrived at an emergency department because of a mild or moderate asthma attack, the main reason for not using spacers was the parent's preference ${ }^{25}$, whereas in our study, the main reason was that spacers were "not recommended by doctors". These results show that there is a major defect in following the global and Saudi guidelines by many physicians leading to improper treatment and control of asthma in our population, which is another factor leading to recurrent visits to the EDs. It is the responsibility of the treating physician to provide proper education regarding the outpatient therapy in bronchial asthma to the caregivers of the asthmatic children. $73.1 \%$ of the children in this study had no follow up outside of the ED. This is an alarming figure in this population who require proper outpatient follow up. This emphasizes the need of a well structured connection between the Asthma clinics and the ED to facilitate and expedite the referral process of those high risk patients to the proper follow up programs in the community. Investing in this "referral system" is likely to pay off in the long term with less ED visits of those patients.

This study gave a snapshot of the awareness and knowledge of the caregivers about asthma in their children in Makkah region; however, certain limitations do exist in this study. First, this is a hospital-based study; hence the findings cannot be generalized to the community level. Second, the sample was a convenient sample limited by the availability of the research team. further studies including the whole region of Makkah and 24-hour coverage should be conducted which will give a better representation of the asthmatic population.

\section{Conclusion}

In this study, a significant percentage of caregivers do not fully understand the concept of Asthma and its chronicity, which in turn, affects their adherence to the management options and follow up. Many of the caregivers also have false beliefs about the triggers, treatment modalities and duration of treatment. Better educational plans and 
adherence to asthma treatment guidelines need to be adopted by pediatricians and Emergency physicians to help overcome those obstacles especially in prescribing ICS and recommending MDIs to families after the ED management.

\section{Acknowledgments}

We thank the administration and staff members of the Maternity and Children's Hospital in Makkah for their collaboration to facilitate this study as well as Dr Samah Alfahmi, Dr Mohammed Khayat, Ruqayya Azhar and Rahaf Alshareef for their contribution in this research.

\section{Ethics Approval and Consent to Participate}

All patients signed informed consent before entering into the study. No study drug or procedure was applied. This is an observational study.

\section{Conflicts of Interest}

The authors declared that they have no competing interests.

\section{References}

1. Ferrante G, La Grutta S. The burden of pediatric asthma. Front Pediatr. 2018; 6:186. https://doi.org/10.3389/ fped.2018.00186. PMid: 29988370, PMCid: PMC6023992.

2. Pearson WS, Goates SA, Harrykissoon SD, Miller SA. Statebased Medicaid costs for pediatric asthma emergency department visits. Prev. Chronic. Dis. 2014; 11:E108. https://doi.org/10.5888/pcd11.140139. PMid: 24967830, PMCid: PMC4075488.

3. BinSaeed AA. Caregiver knowledge and its relationship to asthma control among children in Saudi Arabia. J. Asthma. 2014; 51(8):870-75. https://doi.org/10.3109/02770903.2014 .906608. PMid: 24654707.

4. Herzog R, Cunningham-Rundles S. Pediatric asthma: Natural history, assessment, and treatment. Mt. Sinai. J. Med. 2011; 78(5):645-60. https://doi.org/10.1002/ msj.20285. PMid: 21913196, PMCid: PMC3172616.

5. Fu L-S, Tsai M-C. Asthma exacerbation in children: A practical review. Pediatrics and Neonatology. 2014; 55(2):83-91. https://doi.org/10.1016/j.pedneo.2013.07.004. PMid: 24211086, PMCid: PMC7102856.
6. Al-Jahdali HH, Al-Hajjaj MS, Alanezi MO, Zeitoni MO, Al-Tasan TH. Asthma control assessment using asthma control test among patients attending 5 tertiary care hospitals in Saudi Arabia. Saudi Med. J. 2008; 29(5):714-17.

7. Schatz M, Rachelefsky G, Krishnan JA. Follow-up after acute asthma episodes: What improves future outcomes? Proc. Am. Thorac. Soc. 2009; 6(4):386-93. https://doi.org/10.1513/pats.P09ST6. PMid: 19675349.

8. Wolf FM, Guevara JP, Grum CM, Clark NM, Cates CJ. Educational interventions for asthma in children. Cochrane Database Syst. Rev. 2003: CD000326. https://doi. org/10.1002/14651858. CD000326. PMid: 12535395.

9. Gajanan G, Padbidri VS, Chaudhury A. Assessment of knowledge and attitude of parents towards the allergy and bronchial asthma in their children. Inter. J. Med. Public Health. 2016; 6(3):121-25. https://doi.org/10.5530/ ijmedph.2016.3.5.

10. Al Binali A, Mahfouz A, Al Fifi S, Naser S, Al Gelban K. Asthma knowledge and behaviours among mothers of asthmatic children in Aseer, South-West Saudi Arabia. Eastern Mediterranean Health J. 2010; 16(11):1153-58. https://doi.org/10.26719/2010.16.11.1153.

11. Zaraket R, Al-Tannir MA, Bin Abdulhak AA, Shatila A, Lababidi H. Parental perceptions and beliefs about childhood asthma: A cross-sectional study. Croat. Med. J. 2011; 52(5):637-43. https://doi.org/10.3325/ cmj.2011.52.637. PMid: 21990082, PMCid: PMC3195973.

12. Al-Moamary MS, Alhaider SA, Al-Hajjaj MS. The Saudi initiative for asthma - 2019 update: Guidelines for the diagnosis and management of asthma in adults and children. Ann. Thoracic Med. 2019; 14(1):3-48. https://doi.org/10.4103/atm.ATM_327_18, https://doi. org/10.4103/1817-1737.173196. PMid: 26933455, PMCid: PMC4748613.

13. Weitzman M, Gortmaker S, Walker DK, Sobol A. Maternal smoking and childhood asthma. Pediatrics. 1990; 85(4):505-11.

14. Chilmonczyk BA, Salmun LM, Megathlin KN, Neveux LM, Palomaki GE, Knight GJ, et al. Association between exposure to environmental tobacco smoke and exacerbations of asthma in children. New England J. Med. 1993; 328(23):1665-69. https://doi.org/10.1056/ NEJM199306103282303. PMid: 8487825.

15. Gonzalez MASJ, Gonzalez-Barcala F-J, Pertega S, Sampedro M, Lastres JS, Bamonde L, et al. Impact of parental smoking on childhood asthma. Jornal de Pediatria. 2013; 89(3):29499. https://doi.org/10.1016/j.jped.2012.11.001. PMid: 23684453.

16. Hadnadjev M, Ilić M. Smoking and asthma in children. Medicinski Glasnik. 2011; 8(2):266-72. 
17. Evans D, Levison MJ, Feldman CH, Clark NM, Wasilewski $\mathrm{Y}$, Levin B, et al. The impact of passive smoking on emergency room visits of urban children with asthma. Am Rev. Respiratory Disease. 1987; 135(3):567-72.

18. Al-Rawas OA, Al-Maniri AA, Al-Riyami BM. Home exposure to Arabian incense (bakhour) and asthma symptoms in children: A community survey in two regions in Oman. BMC Pulmonary Med. 2009; 9(1):23-27. https:// doi.org/10.1186/1471-2466-9-23. PMid:19450289, PMCid: PMC2693130.

19. Castro-Rodriguez JA, Rodrigo GJ. Efficacy of inhaled corticosteroids in infants and preschoolers with recurrent wheezing and asthma: A systematic review with metaanalysis. Pediatrics. 2009; 123(3):e519-25. https://doi. org/10.1542/peds.2008-2867. PMid: 19254986.

20. Delgado A, Chou KJ, Silver EJ, Crain EF. Nebulizers vs metered-dose inhalers with spacers for bronchodilator therapy to treat wheezing in children aged 2 to 24 months in a pediatric emergency department. Archives of Pediatrics and Adolescent Medicine. 2003; 157(1):76-80. https://doi. org/10.1001/archpedi.157.1.76. PMid: 12517199.

21. Jamalvi SW, Raza SJ, Naz F, Shamim S, Jamalvi SM. Management of acute asthma in children using metered dose inhaler and small volume nebulizer. J. Pakistan Med. Assoc. 2006; 56(12):595-99.

22. Alhaider S, Alshehri H, Al-Eid K. Replacing nebulizers by MDI-spacers for bronchodilator and inhaled corticosteroid administration: Impact on the utilization of hospital resources. Int. J. Pediatrics and Adolescent Med. 2014; 1(1):26-30. https://doi.org/10.1016/j.ijpam.2014.09.002. PMid: 32289071, PMCid: PMC7104032.

23. Abu-Shaheen AK, Nofal A, Heena H. Parental Perceptions and Practices toward Childhood Asthma. Bio. Med. Research International. 2016; Article ID 6364194. 1-7 https://doi.org/10.1155/2016/6364194. PMid: 27843948, PMCid: PMC5097792.

24. Zaraket R, Al-Tannir MA, Abdulhak B, Aref A, Shatila A, Lababidi H. Parental perceptions and beliefs about childhood asthma: A cross-sectional study. Croatian. Med. J. 2011; 52(5):637-43. https://doi.org/10.3325/ cmj.2011.52.637. PMid: 21990082, PMCid: PMC3195973.

25. Cheng NG, Browne GJ, Lam LT, Yeoh R, Oomens M. Spacer compliance after discharge following a mild to moderate asthma attack. Arch. Dis. Child. 2002; 87:302-05. https:// doi.org/10.1136/adc.87.4.302. PMid: 12244002, PMCid: PMC1763032. 